Provided for non-commercial research and education use. Not for reproduction, distribution or commercial use.

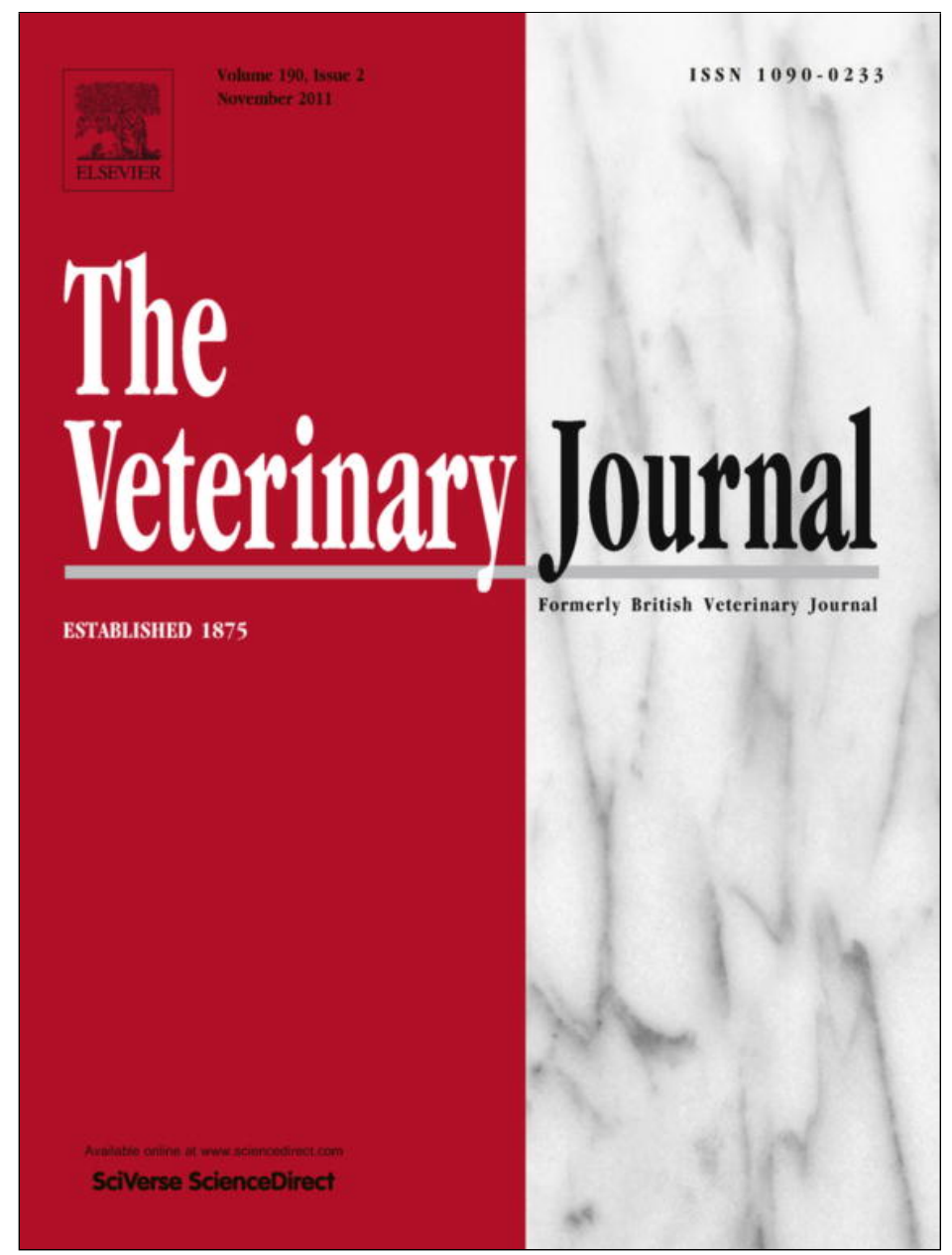

This article appeared in a journal published by Elsevier. The attached copy is furnished to the author for internal non-commercial research and education use, including for instruction at the authors institution and sharing with colleagues.

Other uses, including reproduction and distribution, or selling or licensing copies, or posting to personal, institutional or third party websites are prohibited.

In most cases authors are permitted to post their version of the article (e.g. in Word or Tex form) to their personal website or institutional repository. Authors requiring further information regarding Elsevier's archiving and manuscript policies are encouraged to visit:

http://www.elsevier.com/copyright 
Review

\title{
The influence of animals on the development of children
}

\author{
Nienke Endenburg a,*, Hein A. van Lith ${ }^{\mathrm{b}, \mathrm{c}}$ \\ ${ }^{a}$ Department of Animals in Science and Society, Division of Human-Animal Relationship and Animal Behaviour Clinic, Faculty of Veterinary Medicine, \\ Utrecht University, The Netherlands \\ ${ }^{\mathrm{b}}$ Department of Animals in Sciences and Society, Division of Animal Welfare E Laboratory Animals Science Program Emotion and Cognition, Faculty of Veterinary Medicine, \\ Utrecht University, The Netherlands \\ ${ }^{\mathrm{c}}$ Rudolf Magnus Institute of Neuroscience, University Medical Centre Utrecht, The Netherlands
}

\section{A R T I C L E I N F O}

\section{Article history:}

Accepted 18 November 2010

\section{Keywords:}

Animals

Children

Development

Animal assisted therapy

\begin{abstract}
A B S T R A C T
There is a widespread belief that interaction with an animal is beneficial for the development of children, and several studies (most with methodological shortcomings) have investigated the influence of (companion) animals on the social-emotional and cognitive development of children. In this article, the 1984 model of Professor Jay Belsky has been used to describe which variables influence the development of children and how the companion animal-child interaction influences these variables. The value of the AAA/AAT (Animal Assisted Activities/Animal Assisted Therapy) programmes in children with a wide variety of clinical and social problems, such as behaviour problems and autistic spectrum symptoms, is discussed. The findings suggest that (companion) animals positively influence children's development and have a valuable role in therapy.
\end{abstract}

(c) 2010 Elsevier Ltd. All rights reserved.

\section{Introduction}

Parents often buy their children a companion animal because they think that having an animal to play with and look after is a good thing. Indeed, such parents may consider that having a companion animal helps their children become more responsible and more social, and develops their character (Endenburg, 1991). However, the relationship between humans and animals, and especially the influence of companion animals on children, is a relatively new area of research. To date, research on children's contact with animals involves two distinct groups of studies, namely, those looking at the impact of contact with companion animals on the development of children, and those investigating the use in therapy of animals, such as dogs, horses and dolphins. These programmes are known as Animal Assisted Activities (AAA) and Animal Assisted Therapy (AAT), respectively. Both types of studies are reviewed here. Attention must also be given to the welfare of the animals used in AAA and AAT, but, as Serpell et al. (2006) have stated 'Animal Assisted Intervention has encountered growing popularity in the absence of a systematic assessment of the potential threats to the welfare of the animals'.

Studies of children and animals touch on cognitive, social, and emotional development and involve diverse sub-populations of children. Many early reports were case studies, but in later work questionnaires, surveys, and interview approaches were used.

\footnotetext{
* Corresponding author. Tel.: +31 30253 1565; fax: +31 302537997.

E-mail address: n.endenburg@uu.nl (N. Endenburg).
}

Although several interesting investigations have been reported (see, for example, Nimer and Lundahl, 2007; Melson, 2003), the mechanisms underlying the results remain unclear. A problem with this line of research is that it is difficult (although not impossible) to conduct experimental studies (Endenburg, 1991). For example, it is not feasible to 'force' people to take a companion animal whilst others are told that they are not allowed to do so. It is therefore difficult to say anything about causal relationships. Sometimes in care facilities it is possible to give an animal to certain groups of children but not to other groups, but this type of study is rare and it is difficult to generalise these data to children living with their families under 'normal' circumstances.

Despite the methodological weaknesses of existing studies, the evidence for contact with animals promoting healthy child development is promising (Faber Taylor and Kuo, 2006). Whilst there is ambiguity in the findings of individual studies, the persistence of positive findings across different investigations incorporating different methodological weaknesses makes it likely that this is a real effect.

\section{The development of children}

In order to investigate the influence of animals on children's development, it is first necessary to briefly describe how children develop, using the model of Belsky (1984), which is a process model, to explain the variables that influence child development.

Children have to master tasks concerning cognitive as well as social and emotional development. These tasks represent 
milestones in development. According to Belsky (1984), three domains of variables interact to influence this process, namely, (1) the characteristics of the child, (2) the personal psychological resources of the parents, and (3) the contextual sources of stress and support. The child's characteristics include (at least partly) genetically determined factors (for example, temperament and intelligence), which influence the development of the child, are relatively stable, and are little affected by other variables such as parenting. Temperament refers to those aspects of an individual's personality, such as introversion and extroversion that are often regarded as innate rather than learned (Zentner and Bates, 2008). Intelligence is the aggregate or global capacity of the individual to act purposefully, to think rationally, and to deal effectively with his environment (Wechsler, 1944). Of the personal psychological resources of the parents, 'personality', 'work of parents', 'marital relations', and the 'parenting style' are important factors, and of the contextual sources of stress and support, 'social network' and 'peer group' may be important (Fig. 1). Social networks mean, for instance, a religious group, co-workers or sports clubs. Social networks are clearly different depending on the person.

When we talk about 'child development', we mean a combination of social-emotional development and cognitive development. Social-emotional development can be measured by self-esteem and a positive social orientation of the child, but social skills and a sense of social or moral responsibility can also contribute to the building of self-esteem. Self-esteem is a term used to reflect a person's overall evaluation or appraisal of his or her own worth (Rosenberg, 1963). Cognitive development can be assessed when children learn to read, write, and are able to do mathematics. How a child develops is also influenced by the child's social network: the social development of a child without friends is very different from that of a child with many friends. For example, the support provided by social networks can enhance self-esteem (Cochran and Brassard, 1979) and contribute to mental health, possibly by providing a buffering, protective function against psychosocial stress (Cohen and Wills, 1985; Parry and Shapiro, 1986).

Obviously, parents and parenting styles also influence how a child develops. Parental use of induction or reasoning, consistent discipline, and expressions of warmth are positively related to self-esteem and intellectual achievement during the school-age years (Belsky, 1984). Parents should be sensitive to the needs of their children. The model of parental functioning assumes that there is a link between the parents' psychological well-being and their functioning as parents, which in turn reflects their own experiences while growing up (Belsky et al., 2007). Other factors, such as marital relations, also influence parenting. Belsky (1984) found that a positive marital relationship was a major factor supporting competent parenting. In a single parent family this kind of support will not be available, and when parents disagree about how to raise their children there is also no such support.

Social networks can also have a beneficial influence on parenting as they provide emotional support. This support can be defined as the love and interpersonal acceptance an individual receives from others, either through explicit statements to that effect or as a result of considerate actions (Belsky, 1984), so that people feel cared for and accepted. The work status of the parents also influences parenting. Unemployment can introduce stress into the family and will also influence the financial status (Baarda, 1988). Financial strain is more salient for people of lower socio-economic status, and a damage to sense of self for the victims of job loss for those of a higher socio-economic status (Blake Turner, 1995). In general, being unemployed was seen as more negative than attractive for welfare benefits (Taris et al., 1995). If both parents work, children may have other forms of daytime care, although there is no evidence that this has a significant negative or positive influence on their development (Heath and McKenry, 1989).

There are other models of child development (Conger et al., 1992; Petterson and Burke Albers, 2001). The reason why the model of Belsky was chosen here is that it looks at three parts, namely, (1) personal psychological resources of the parents; (2) characteristics of the child, and (3) contextual sources of stress and support (this can be through grandparents, relatives and/or the community at large). Other models only look at a certain part, such as poverty of maternal depression on the development of children.

Although other factors not included in Belsky's model will influence a child's development, the model provides a useful framework

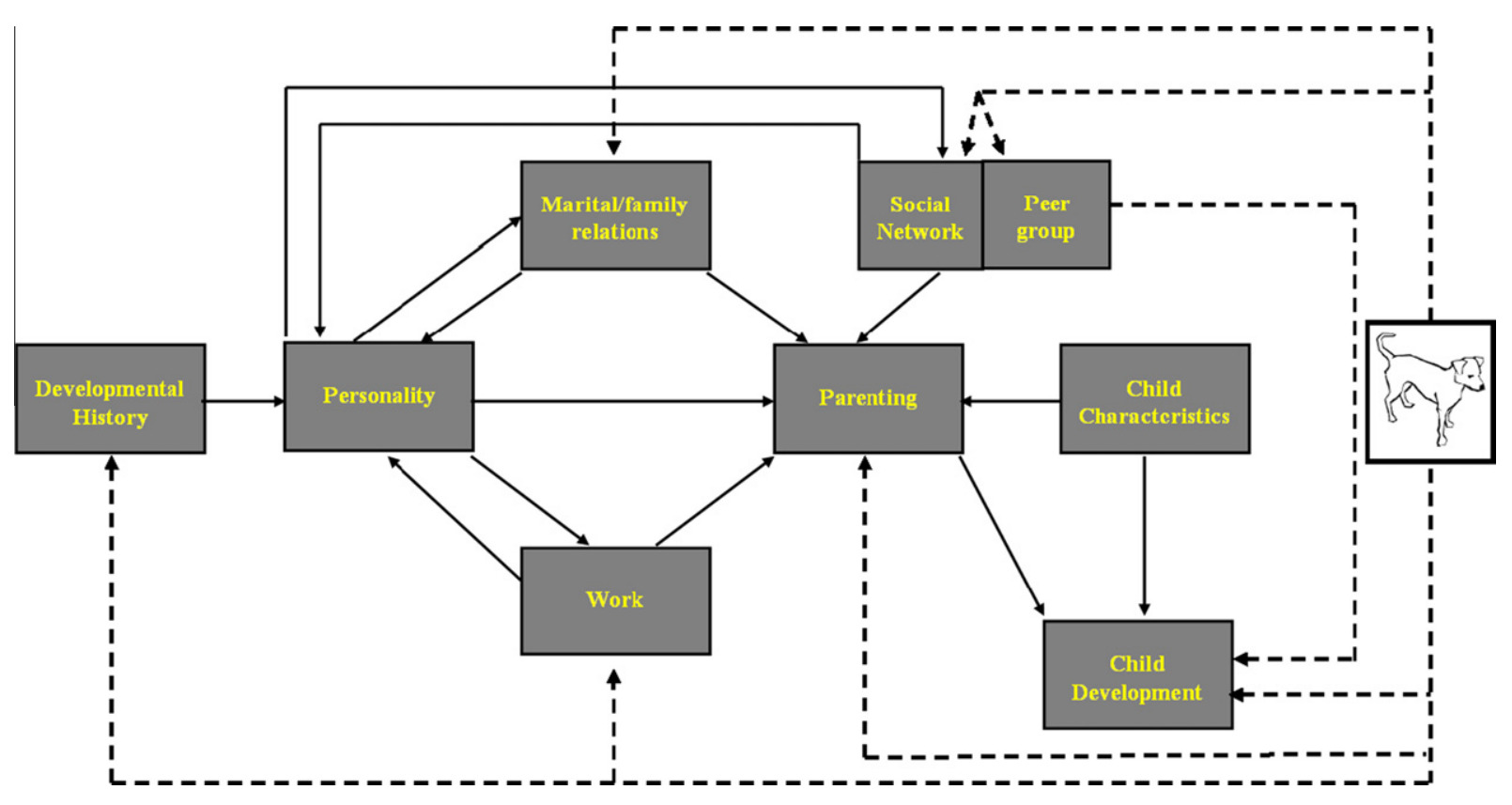

Fig. 1. A process model of the determinants of child development and the possible influence of companion animals. 
for examining the potential influence of companion animals on the development of children. The variables, as illustrated in Fig. 1, are not independent of but influence each other as the development of children is a dynamic process.

\section{Emotional development}

Companion animals may play a special role in the emotional development of children, particularly in the development of selfesteem, autonomy, and empathy for others (Wilks, 1999). In a 9month study on the effects of keeping companion animals in a school classroom, Bergesen (1989) found that the children's selfesteem scores increased significantly. Covert et al. (1985) found that teenagers who owned companion animals scored higher on a measure of self-esteem than those who did not. Another study found that adults' self-concept was related to the age when they first bonded with a companion animal: those who had a first companion animal during their teenage years or when they were younger than 6 years scored higher on a measure of self-concept than adults who had a first companion animal between the ages of 6 and 12 (Poresky et al., 1988a,b). It was not mentioned whether or not these children were given the chief responsibility for the animal, but the companion animal and child were in the same household. By self-concept we mean here the mental image or perception that one has of oneself (Poresky et al., 1988a,b). The term 'bonding' refers to the process of attachment that develops between close friends, parents and children (Bowlby, 1990).

This interaction with age of the effects of companion animals on self-esteem or self-concept has been reported by others. For instance, Van Houtte and Jarvis (1995) found significant differences in fifth and sixth grade participants, where those children who owned companion animals had higher self-esteem than those without animals; on the other hand third and fourth grade companion animal owners did not score significantly higher on self-esteem than non-companion animal owners. These findings suggest that companion animals have their greatest influence on children as they approach adolescence. This might be because children are given greater responsibility for the companion animal or because children experience more problems or uncertainty and need the emotional support they derive from their companion animals.

Bryant and Whorley (1989) found that children's use of their companion animals for emotional support was most clearly related to a good experience of such support from their parents. This means that when children have had emotional support from their parents, they were better able to receive this kind of support from companion animals. Poresky and Hendrix (1989) also found that those children with companion animals and a better home environment showed higher age-adjusted child development scores. Thus it would appear that a good home environment makes children more receptive to the social support provided by companion animals.

A study examining self-esteem in early adolescence revealed that participants ranked a companion animal below parents but above other social referents on a list of things that made them feel good or satisfied with themselves (Juhasz, 1985). It is worth noting that two non-companion animal studies involving random assignment to conditions with and without animals also linked increased self-esteem/self-concept with animals. In a study by Dismuke (1984), children interacting with horses during therapy sessions had a greater increase in scores on a measure of self-esteem than those receiving therapy without a horse. In work by Katcher and Gregory (2000), youths who participated in a programme that incorporated hands-on learning with animals and natural ecosystems scored higher on a measure of self-concept than youths participating in the regular school programme. Companion animals appear to positively influence emotional development, with age and the home environment appearing to be important mediators of this effect.

\section{Social development}

Children who grow up in a household with dogs exhibited greater social competence and developed into more socially competent adults than other children (Guttman et al., 1985; Melson et al., 1989; Endenburg and Baarda, 1995; Melson, 1995). By social competence is meant the condition of possessing the social, emotional and intellectual skills and behaviours needed to succeed as a member of society (Owens and Johnston-Rodriguez, 2010). Social competence will make it easier for children to belong to a social network, which itself can provide support, and higher levels of social support are associated with positive effects on various diseases and stress-buffering effects (Heinrichs et al., 2003).

It has been suggested that companion animals enhance social interactions between people, and increase or strengthen social networks and social provisions in children, increasing their psychological well-being (McNicholas and Collis, 2000). Measures of social competence include observed or reported levels of social skills, social preference, peer status, pro-social behaviour, or developmentally appropriate social play behaviour (e.g., social pretend or co-operative play for preschoolers) (Trentacosta and Fine, 2010). Guttman (1984) found that boys who owned a companion animal performed better on measures of their capacity for decoding non-verbal information, potentially making them better at communication, than boys who did not.

An important factor in social development is empathy, i.e. the perceived emotional experience of another person (Daly and Morton, 2006). Empathy with animals, such as the ability to perceive their needs, seems to have a transfer effect to empathy with people (Ascione, 1992), and is therefore a basis for the development of social intelligence (Kidd and Kidd, 1987). Children who own companion animals tend to score higher on an empathy scale than children who do not (Bryant, 1986; Melson and Fogel, 1989; Ascione and Weber, 1996; Paul, 2000). Hergovich et al. (2002) also found an increase in empathy that may be the result of the presence of a companion animal, but lasting effects have not been consistently examined. One study (Ascione and Weber, 1996) found that humane attitudes persisted at the time of a post-test conducted at Year Two follow-up but it did not specifically address empathy. Research has shown that children who have a positive attitude towards companion animals are more empathic than those who have a negative, or less positive, attitude (Daly and Morton, 2006).

But which animal factors influence empathy? Poresky (1990, 1996) and Poresky et al. (1987) found that owning a companion animal is much less important for social competence than bonding with the animal. They found that attachment between the child and its companion animal was a more reliable measure than owning a companion animal per se. Attachment is mostly used in the psychological field where there are many studies about this topic, mostly pertaining to the attachment between mother and child (Endenburg, 1991). According to Ainsworth et al. (1978) 'attachment is the term for a relatively durable affective relationship between a child and one or more specific persons with whom it interacts regularly'. Many owners consider their companion animal to be a part of the family, treat it as a child and speak to it (Wells, 2009).

Three studies have found that young children with a strong bond or close relationship with their companion animal scored higher on a measure of empathy than children with a weak relationship with their companion animal (Poresky, 1990, 1996; Vidovic et al., 1999), and children without a companion animal (Vidovic et al., 1999). 
Thus attachment to companion animals may have a moderating effect. Melson (1988) has shown that involvement with a companion animal (and not simply companion animal ownership) is related to children's involvement in non-school social activities (preschoolers: $r=0.51, P<0.0011$; second graders: $r=0.48, P<$ 0.0001 ; fifth graders: $r=0.55, P<0.0001$ and boys: $r=0.50$, $P<0.0001$; girls: $r=0.52, P<0.0001)$. This was also found in the study of Daly and Morton (2006) and is consistent with the study of Vidovic et al. (1999) in which children strongly attached to their companion animals scored not only higher on empathy and prosocial behaviour scales, but also rated their family climate in a more favourable way than did children who were less attached to their companion animals. Bodsworth and Coleman (2001) reported that differences in the degree to which children were attached to their companion animals were associated with singleor two-parent family environments. Children from one-parent families were significantly more attached to their dogs. Strand (2004) suggested that child attachment to companion animals plays a buffering role during parental strife. Further research is required to show whether or not attachment and involvement are the same concepts in this context.

We must also ask whether or not children with a specific animal preference are more empathic than those with another preference or with no preference at all. Vidovic et al. (1999) found that only dog owners (i.e. those having at least one dog) were more empathic than non-owners (i.e. having no companion animal), and similar results were obtained for prosocial orientation. Age can also influence social behaviour. In a study in which animals (mainly dogs) were present in school classes, teachers reported higher social integration and a decrease in the number of aggressive children. The mean age of the children was 6.7 years (Kotrschal and Ortbauer, 2003). Melson et al. (1991) found that 5-year-old boys and fifth-grade boys and girls who were attached to a companion animal at home scored higher on measures of empathy, but that this was not so clear-cut in secondary school children. Melson et al. (1991) also found that the perceived emotional and cognitive competence of primary school children was related to their attachment to a companion animal. Accordingly, other factors, such as age, could have a mediating effect on the association between companion animals and empathy (Poresky et al., 1988a,b; Melson, 1988; Melson et al., 1991).

\section{Cognitive development}

Numerous studies have investigated the influence of companion animals on the social and emotional development of children, but few have investigated their influence on the cognitive development. Poresky et al. (1987) found that improved cognitive development was associated with the bond between children and companion animals. It has been suggested that companion animal ownership may facilitate language acquisition and enhance verbal skills in children. This would occur as a result of the companion animal functioning both as a patient recipient of the young child's babble and as an attractive verbal stimulus, eliciting communication from the child in the form of praise, orders, encouragement, and punishment.

Are there reasons why the interaction with animals could influence the cognitive development? Hatano and Inagaki (1993) indicated that a living animal presents 'inherently occurring variations in its critical parameters'. Or, in other words, animals are 'predictably unpredictable' (Melson, 2003). To the observing child, animal behaviour embodies what Piaget (1969) argues is the engine of all learning, namely, cognitive incongruity, moderate discrepancy from established schema, and novel information. Moreover, for many children, companion animals are likely to be powerful moti- vators for learning, for at least two well-established reasons: (1) children learn and retain more about subjects in which they are emotionally invested (Hatano and Inagaki, 1993) and (2) children's learning is optimised when it occurs within meaningful relationships (Vygotsky, 1978).

Research on cognitive development has also been done in the field of AAA/AAT programmes. Companion animals (as well as dolphins) have been used to increase children's concentration span and as a motivator to help children learn. Some people with severe disabilities have a problem with concentration rather than with the processing of information. Nathanson et al. (1997) found that such individuals could concentrate better when they worked with dolphins because they were interested in the dolphin. Moreover, they were also more motivated to learn because they were rewarded with being allowed to play and swim with the dolphin. This way of learning was facilitated by the dolphins and, according to Nathanson (1998), was 2-10 times more effective than traditional forms of therapy. However, no real evidence has yet been offered to support these hypotheses (Marino and Lilienfeld, 2007). More research is needed to find out whether companion animals can also influence cognitive development.

\section{AAA/AAT}

The advent of scientific medicine toward the end of the 19th century had the effect of displacing companion animals from therapeutic settings. Freud (1959) saw animal images as the uncontrollable impulses as a threat of the human ego, and Shafton (1995) stated that mental illness was (in the opinion of Freud) a result when bottled-up animal drives found no healthy or creative outlet and erupt uncontrollably into consciousness.

One of the first researchers to study the interaction between children and companion animals was Boris Levinson (1969). As a psychotherapist he did several case studies, although his fellow psychologists were not very enthusiastic about the idea that animals could help children in their development (Kruger and Serpell, 2006). Companion animals were seen as inferior replacements for human social interactions. However, since the mid-1980s, and at least partly in response to the scepticism of the medical establishment, the theoretical emphasis has shifted away from these relatively metaphysical ideas about animals as psycho-spiritual mediators toward more prosaic, scientifically 'respectable' explanations for the apparent therapeutic benefits of animal companionship (Serpell, 2000).

Today, more and more animals are being introduced to individuals struggling with a malady in nursing homes or hospitals. This is known as Animal Assisted Activities (AAA). The emphasis is on recreational activities in contrast to AAT, in which an animal is included in the treatment plan. Generally, AAT involves a credentialed treatment provider who guides interactions between a patient and an animal to achieve specific goals (Chandler, 2005). So, the introduction of an animal is designed to accomplish predefined outcomes believed to be difficult to achieve otherwise or outcomes best addressed through exposure to an animal.

AAT has been practiced for many years and there is now increasing interest in establishing its efficacy (Barker, 1999; Nimer and Lundahl, 2007). AAT has been applied in a variety of healthcare settings. It has been used as an adjunct to physical therapy, with patients being asked to walk a dog, pet or brush a cat, or play fetch with a dog; i.e. activities designed to increase muscle strength and improve control of fine motor skills (Chandler, 2005). For example, a child might be encouraged to gently pet and talk to an animal to teach appropriate touch, reduce anxiety, increase a sense of connection to a living being, reduce loneliness, and develop a variety of skills (Chandler, 2005; Delta Society, 2006). 
AAT has been applied to a wide variety of clinical problems, such as autistic spectrum symptoms (Redefer and Goodman, 1989), medical conditions (Havenar et al., 2001), compromised mental functioning (Kanamori et al., 2001), emotional difficulties (Barker and Dawson, 1998), undesirable behaviours (Nagengast et al., 1997), and physical problems (Nathanson et al., 1997). The use of an animal in therapy may be beneficial because animals seem to have a natural tendency to create a bond with people (Olbrich and Otterstedt, 2003). Animals may promote a warm and safe atmosphere that can be independently therapeutic and help clients accept interventions offered by the treatment provider. AAT is not generally viewed as a stand-alone treatment but rather animals are used as a supplement or in conjunction with other interventions. AAT has been used with individuals across the lifespan, including children, adolescents, adults, and the elderly. However, not much research has been done to identify which animals can be used with which type of psychological problems (Serpell et al., 2006).

The delivery of AAT varies according to the type of animal involved (such as dogs, horses etc.), the setting in which it is delivered (such as inpatient or outpatient environment, medical clinic, short- or long-term facility), the duration of the intervention (short- or long-term), and whether the intervention is delivered in a group or individual format. Some investigations have used rigorous methodology, using randomised designs comparing AAT with control groups or established treatments (such as recreational therapy), whilst others have used simple pre-/post-test designs (Nimer and Lundahl, 2007).

A well designed study in the field of AAT was done by Berget et al. (2008) on adults with psychiatric disorders. It was a randomized controlled trial with follow-up. Two-thirds of the patients $(n=60)$ were given a 12 -week intervention with farm animals. It was found that AAT with farm animals may have positive influences on self-efficacy and coping ability among psychiatric patients with long lasting psychiatric symptoms. No changes were found in quality of life.

The same is true of the study done by Antonioli and Reveley (2005) on the influence of dolphins on depression. This was a single blind, randomised, controlled trial done with 30 patients randomly assigned to two groups, one experimental and one control. The experimental group interacted with the dolphins for 2 weeks, every day for one hour. The control group was assigned to an outdoor nature programme featuring the same water activities as the animal care programme but in the absence of dolphins, to control for the influence of water and other, non-specific, environmental factors. The therapy with the dolphins was effective in alleviating symptoms of depression.

But in AAT/AAA the welfare of the animal has to be taken into consideration. Unfortunately until now not much research has been done on this topic and there is no systematic assessment of the potential threats to the welfare of the animals (Serpell et al., 2006). Haubenhofer and Kirchengast $(2006,2007)$ found that AAT had an influence on the cortisol levels of dogs but further research has to be done to find out whether these physiological responses are indicative of potentially negative stress or of positive excitement (Haubenhofer and Kirchengast, 2006). Other research has indicated that workload, inadequate environmental conditions and client age, might all contribute to an increase in a dog's stress level (Marinelli et al., 2009). This is also true for dolphins, apart from the fact that dolphins are large, strong, wild animals and are unpredictable, even when well-trained (Williamson, 2008).

Companion animals can contribute to the psychological health of children and adults (Wells, 2009). Social contacts will be improved when walking a dog (Wells, 2004). Especially for individuals with disabilities a service dog can be very important, not just for helping this person but to normalize interactions with other people (Guest et al., 2006). Reviews have been published about the influence of companion animal ownership and human, adults as well as children's, health (McNicholas et al., 2005; Barker and Wolen, 2008). It was found that companion animal owners had a higher survival rate from myocardial infarction, a significantly lower use of general practitioner services, a reduced risk of asthma and allergic rhinitis in children exposed to companion animal allergens during the first year of life, a reduced risk of cardiovascular disease and better physical and psychological well-being in community dwelling older people. However recent studies have not always replicated these benefits. Conflicting findings may be explained by confounding variables that have not been controlled for in several studies. It is important to investigate mediating variables that may play a role in the physiological benefits of companion animal ownership.

\section{Research difficulties}

So, studies are not unanimous in their findings on the influence of companion animals on the development of children, with some workers showing the presence of an association and others not. It is unclear whether this association, if present, is due to pre-existing differences in the types of family that choose to have companion animals versus those that do not, or the types of children who form bonds with companion animals versus those who do not. Research has shown that when the family climate is empathic and supportive, children are better able to receive the support of animals (Bryant and Whorley, 1989). In other words, socially oriented, empathic children are more likely to bond with their companion animals, and socially oriented, empathic parents may be more likely to get companion animals for their children (Faber Taylor and Kuo, 2006). Whether or not there are negative consequences in living together with companion animals, other than zoonoses (Overgaauw et al., 2009), allergic reactions (Anyo et al., 2002), and (fatal) injuries because of bite incidences (Sacks et al., 1996) is to date unknown.

Children growing up with companion animals generally show higher levels of self-esteem, empathy, and responsibility, and develop into socially more competent adults than children who do not grow up with companion animals (for review, see Endenburg and Baarda, 1995). However, in these studies the family environment can never be excluded as a confounding variable. Potentially, the 'social climate' in families with companion animals may be different to that in families without companion animals. This makes the causal effects of parenting style on the development of children difficult to disentangle from the contribution made by companion animals (Kotrschal and Ortbauer, 2003). What is needed is random assignment of participants to conditions rather than participantselected assignment to conditions (Wilson and Barker, 2003).

The problem is that a causal relationship cannot be established because it is unclear whether empathic people obtain companion animals or whether owning a companion animal makes a person more empathic. Because of the nature of the independent variable, owning a companion animal or not, research in this field cannot be truly experimental (Van Houtte and Jarvis, 1995). Because most published studies are correlational, longitudinal studies are needed to establish causality, but so far these are rare (Endenburg and Baarda, 1995; Wilson and Barker, 2003). The concern about correlational types of studies is the tendency to ascribe causality to relationships between variables (Wilson and Barker, 2003). Longitudinal studies are also needed because not much is known about the effects of animals over a longer period of time.

The same is true for studies of AAA/AAT. Lack of financial support has meant that only small convenience samples have been used in the few studies performed so far. Moreover, while qualitative reviews are helpful in detecting patterns, such reviews are 
limited because of their subjective quality and inability to test hypotheses (Wilson and Barker, 2003). Furthermore, little attention has been paid to animal welfare aspects. There is a need for studies of the possible health effects that people have on animals, for studies that look at the animal side of the human bond (Beck and Katcher, 2003), as well as how the welfare of animals can be protected in the best possible way.

Further work is required to identify which animals are best suited for particular types of problems. Are certain farm animals, say pigs, better to work with children who suffer from attention deficit hyperactivity disorder (ADHD)? What are the advantages (and disadvantages) of different animals? To date not much is known about this.

\section{Conclusions}

Although most studies performed to date had methodological weaknesses, the pattern of findings points in the same direction and persists across different sub-populations of children and different settings, namely, that companion animals can promote healthy child development. The studies described here are not unanimous in their findings regarding the influence of companion animals on the development of children, but the pattern points in the same direction and indicates that companion animals can promote healthy child development. In the future, longitudinal studies will be necessary to establish causality and the possible influence of the family climate.

\section{Conflict of interest statement}

None of the authors of this paper has a financial or personal relationship with other people or organisation that could inappropriately influence or bias the content of the paper.

\section{References}

Ainsworth, M.D.S., Blehar, M.C., Waters, E., Wall, S., 1978. Patterns of Attachment. A Psychological Study of the Strange Situation. Erlbaum, Hillsdale.

Antonioli, C., Reveley, M.A., 2005. Randomised controlled trial of animal facilitated therapy with dolphins in the treatment of depression. British Medical Journal 331, 1231-1235.

Anyo, G., Brunekreef, B., de Meer, G., Aarts, F., Janssen, N.A.H., van Vliet, P., 2002. Early, current and past pet ownership: associations with sensitization, bronchial responsiveness and allergic symptoms in school children. Clinical and Experimental Allergy 32, 361-366.

Ascione, F.R., 1992. Enhancing children's attitudes about the humane treatment of animals: generalization to human directed empathy. Anthrozoös 5, 176-191.

Ascione, F.R. Weber C.V 1996. Children's attitudes about the humane treatment of animals and empathy: one-year follow up of a school-based intervention. Anthrozoös 9, 188-195.

Baarda, D.B., 1988. Schoolprestaties van kinderen van werkloze vaders. Thesis, Utrecht University.

Barker, S.B., Dawson, K.S., 1998. The effects of animal-assisted therapy on anxiety ratings of hospitalized psychiatric patients. Psychiatric Services 49, 797-801.

Barker, S.B., 1999. Therapeutic aspects of the human-companion animal interaction. Psychiatric Times 16, 45-47.

Barker, S.B., Wolen, A.R., 2008. The benefits of human-animal interaction: a review. Journal of Veterinary Medical Education 35, 487-495.

Beck, A.M., Katcher, A.H., 2003. Future directions in human-animal bond research. American Behavioral Scientist 47, 79-84.

Belsky, J., 1984. The determinants of parenting. A process model. Child Development 55, 83-96.

Belsky, J., Steinberg, L.D., Houts, R.M., Friedman, S.L., DeHart, G., Cauffman, E., Roisman, G.I., Halpern-Felsher, B.L., Susman, E., 2007. Family rearing antecedents of pubertal timing. Child Development 78, 1302-1321.

Bergesen, F.J., 1989. The effects of pet facilitated therapy on the self-esteem and socialization of primary school children. Presented at the 5th International Conference on the Relationship between Humans and Animals. Monaco, 1989.

Berget, B., Ekeberg, O., Braastad, B.O., 2008. Animal-assisted therapy with farm animals for persons with psychiatric disorders: effects on self-efficacy, coping ability and quality of life, a randomized controlled trial. Clinical Practice and Epidemiology in Mental Health 4, 9-15.

Blake Turner, J., 1995. Economic context and the health effects of unemployment. Journal of Health and Social Behaviour 36, 213-229.
Bodsworth, W., Coleman, G.J., 2001. Child-companion animal attachment bonds in single- and two-parent families. Anthrozoös 14, 216-223.

Bowlby, J., 1990. The Making and Breaking of Affectional Bond. Routledge, New York.

Bryant, B.K., 1986. The relevance of family and neighbourhood animals to socialemotional development in middle childhood. Presented at the Delta Society International Conference, Boston, Massachusetts.

Bryant, B.K., Whorley, P., 1989. Child-pet relationships under conditions of maternal unavailability. Paper Presented at the 5th International Conference on the Relationship between Humans and Animals. Monaco.

Chandler, C.K., 2005. Animal Assisted Therapy in Counselling. Routledge, New York.

Cochran, M., Brassard, J., 1979. Child development and personal social networks. Child Development 50, 601-616.

Cohen, S., Wills, T.A., 1985. Stress, social support and the buffering hypothesis. Psychological Bulletin 98, 310-357.

Conger, R.D., Conger, K.J., Elder, G.H., Lorenz, F.O., Simons, R.L., Whitbeck, L.B. 1992. A family process model of economic hardship and adjustment of early adolescent boys. Child Development 3, 526-541.

Covert, A.M., Whiren, A.P., Keith, J., Nelson, C., 1985. Pets, early adolescents, and families. In: Sussman, M.B. (Ed.), Pets and the Family. The Haworth Press, New York, pp. 95-108.

Daly, B., Morton, L.L., 2006. An investigation of human-animal interactions and empathy as related to pet preference, ownership, attachment, and attitudes in children. Anthrozoös 19, 113-127.

Delta Society, 2006. Introduction to Animal-assisted Activities and Therapy (AAA/ AAT). www.DeltaSociety.org.

Dismuke, R.P., 1984. Rehabilitative horseback riding for children with language disorders. In: Anderson, R.K., Hart, B.L., Hart, L.A. (Eds.), The Pet Connection: Its Influence on Our Health and Quality of Life. Censhare, Minneapolis, pp. 131140.

Endenburg, N., 1991. Animals as Companions; Demographic, Motivational and Ethical Aspects of Companion Animal Ownership. Thesis, University of Amsterdam.

Endenburg, N., Baarda, D.B., 1995. The roles of pets in enhancing human well-being: effects on child development. In: Robinson, I. (Ed.), The Waltham Book of Human-Animal Interaction: Benefits and Responsibilities of Pet Ownership. Pergamon, Exeter, pp. 1-17.

Faber Taylor, A., Kuo, F.E., 2006. Is contact with nature important for healthy child development? State of evidence. In: Spencer, C., Blades, M. (Eds.), Children and their Environments. Cambridge University Press, Cambridge UK, pp. 124-140.

Freud, S., 1959. The Interpretation of Dreams. Basic Books, New York (Translated by Strachey, J.).

Guest, C.M., Collis, G.M., McNicholas, J., 2006. Hearing dogs: a longitudinal study of social and psychological effects on deaf and hard-of-hearing recipients. Journal of Deaf Studies and Deaf Education 11, 252-261.

Guttman, G., 1984. The pet: a tutor to social skills. Journal of the Delta Society 1, 3738.

Guttman, G., Predovic, M., Zemanek, M., 1985. The influence of pet ownership in non-verbal communication and social competence in children. In: Proceedings of the International Symposium on the Human-Pet Relationship, Vienna, pp. $58-63$.

Hatano, G., Inagaki, K., 1993. Desituating cognition through the construction of conceptual knowledge. In: Salomon, G. (Ed.), Distributed Cognitions. Cambridge University Press, New York, pp. 115-133.

Haubenhofer, D.K., Kirchengast, S., 2006. Physiological arousal for companion dogs working with their owners in animal-assisted activities and animal-assisted therapy. Journal of Applied Animal Welfare Science 9, 165-172.

Haubenhofer, D.K., Kirchengast, S., 2007. Dog handlers' and dogs' emotional and cortisol secretion responses associated with animal-assisted therapy sessions. Society and Animals 15, 127-150.

Havenar, L., Gentes, L., Thaler, B., Megel, M.E., Baun, M.M., Driscoll, F.A., Beiraghi, S., Agrawl, N., 2001. The effects of a companion animal on distress in children undergoing dental procedures. Comprehensive Pediatric Nursing 24, 137-152.

Heath, T.D., McKenry, P.C., 1989. Potential benefits of companion animals for selfcare children. Childhood Education 7, 311-314.

Heinrichs, M., Baumgartner, T., Kirschbaum, C., Ehlert, U., 2003. Social support and oxytocin interact to suppress cortisol and subjective responses to psychosocial stress. Biological Psychiatry 54, 1389-1398.

Hergovich, A., Monshi, B., Semmler, G., Zieglmayer, V., 2002. The effects of the presence of a dog in the classroom. Anthrozoös 15, 37-50.

Juhasz, A., 1985. Measuring self-esteem in early adolescent. Adolescence 20, 877887.

Kanamori, M., Suzuki, M., Yamamoto, K., Kanda, M., Matsui, Y., Kojima, E., Fukawa, H., Sugita, T., Oshiro, H., 2001. A day care program and evaluation of animalassisted therapy (AAT) for the elderly with senile dementia. American Journal of Alzheimer's Disease and Other Dementias 16, 234-239.

Katcher, A.H.W., Gregory, G., 2000. The centaur's lessons: therapeutic education through care of animals and nature study. In: Fine, A.H. (Ed.), Handbook on Animal-assisted Therapy: Theoretical Foundations and Guidelines for Practice. Academic Press, San Diego, pp. 153-177.

Kidd, A.H., Kidd, R.M., 1987. Seeking a theory of the human/companion animal bond. Anthrozoös 1, 140-157.

Kotrschal, K., Ortbauer, B., 2003. Behavioural effects of the presence of a dog in a classroom. Anthrozoös 16, 147-159.

Kruger, K.A., Serpell, J.A., 2006. Animal-Assisted interventions in mental health: definitions and theoretical foundations. In: Fine, A.H. (Ed) Handbook on 
Animal-assisted Therapy: Theoretical Foundations and Guidelines for Practice, second ed. Academic Press, San Diego, pp. 21-38.

Levinson, B.M., 1969. Pet-oriented Child Psychotherapy. Charles C. Thomas, Springfield, Illinois.

Marinelli, L., Normando, S., Siliprandi, C., Salvadoretti, M., Mongillo, P., 2009. Dog assisted interventions in a specialized centre and potential concerns for animal welfare. Veterinary Research Communications 33, 93-95.

Marino, L., Lilienfeld, S.O., 2007. Dolphin-assisted therapy: more flawed data and more flawed conclusions. Anthrozoös 20, 239-249.

McNicholas, J., Collis, G.M., 2000. Dogs as catalysts for social interactions: robustness of the effect. British Journal of Psychology 91, 61-70.

McNicholas, J., Gilbey, A., Rennie, A., Ahmedzai, S., Dono, J.A., Ormerod, E., 2005. Pet ownership and human health: a brief review of evidence and issues. British Medical Journal 331, 1252-1254

Melson, G.F., 1988. Availability of and involvement with pets by children determinants and correlates. Anthrozoös 2, 45-52.

Melson, G.F., Fogel, A., 1989. Children's ideas about animal young and their care: a reassessment of gender differences in the development of nurturance. Anthrozoös 2, 265-273.

Melson, G.F., Sparks, C., Peet, S., 1989. Children's ideas about pets and their care. Paper Presented at the Annual Meeting of the Delta Society, November 10-12, Parsipanny, New Jersey.

Melson, G.F., Peet, S., Sparks, C., 1991. Children's attachment to their pets: links to socio-emotional development. Children's Environments Quarterly 8, 55-65.

Melson, G.F., 1995. The role of companion animals in human development. Pape Presented at 'Animals, Health and Quality of Life' 7th International Conference on Human-Animal Interactions, Geneva.

Melson, G.F., 2003. Child development and the human-companion animal bond American Behavioural Scientist 47, 31-39.

Nagengast, S.L. Baun, M.M. Megel, M., Leibowitz, J.M. 1997. The effects of the presence of a companion animal on physiological arousal and behavioura distress in children during a physical examination. Journal of Pediatric Nursing $12,323-330$.

Nathanson, D.E., Castro, D., Friend, H., McMahon, M., 1997. Effectiveness of shortterm dolphin-assisted therapy for children with severe disabilities. Anthrozoös $10,90-100$

Nathanson, D.E., 1998. Long-term effectiveness of dolphin-assisted therapy for children with severe disabilities. Anthozoös 11, 22-32.

Nimer, J., Lundahl, B., 2007. Animal-assisted therapy: a meta-analysis. Anthrozoös 20, 225-238.

Olbrich, E., Otterstedt, E., 2003. Menschen brauchen Tiere: Grundlangen und Praxis der tiergestützten Pädagogik und Therapie. Frankh-Kosmos, Stuttgart.

Overgaauw, P.A.M., van Zuthen, L., Hoek, D., Yaya, F.O., Roelfsema, J., Pinelli, E., van Knapen, F., Kortbeek, L.M., 2009. Zoonotic parasites in fecal samples and fur from dogs and cats in the Netherlands. Veterinary Parasitology 163, 115-122.

Owens, L.A., Johnston-Rodriguez, S., 2010. Social competence. International Encyclopedia of Education, 865-869.

Parry, G., Shapiro, D.A., 1986. Social support and life events in working class women: stress buffering or independent effects. Archives of General Psychiatry 43, 315-323.

Paul, E.S., 2000. Empathy with animals and with humans: are they linked? Anthrozoös 13, 194-202.

Petterson, S.M., Burke Albers, A., 2001. Effects of poverty and maternal depression on early child development. Child Development 72, 1794-1813.

Piaget, J., 1969. The Mechanisms of Perception. Routledge and Paul, London.

Poresky, R.H., Hendrix, C., Mosier, J.E., Samuelson, M.L., 1987. The companion animal bonding scale: internal reliability and construct validity. Psychological Reports 60, 743-746.
Poresky, R.H., Hendrix, C., Mosier, J.E., Samuelson, M.L., 1988a. Young children's companion animal bonding and adults' pet attitudes: a retrospective study. Psychological Reports 62, 419-425.

Poresky, R.P., Hendrix, C., 1989. Companion animal bonding, children's home environments and young children's social development. Paper Presented at the Biennial Meeting of the Society for Research in Child Development, Kansas City, MI, USA.

Poresky, R.H., 1990. The young children's empathy measure: reliability, validity and effects of companion animal bonding. Psychological Reports 66, 931-936.

Poresky, R.H., 1996. Companion animals and other factors affecting young children's development. Anthrozoös 9, 159-168.

Poresky, R.H., Hendrix, C., Mosier, J.E., Samuelson, M.L., 1988b. Children's pets and adults' self-concepts. Journal of Psychology 122, 463-469.

Redefer, L.A., Goodman, J.F., 1989. Brief report: pet-facilitated therapy with autistic children. Journal of Autism and Developmental Disorders 19, 461-467.

Rosenberg, M., 1963. Society and the Adolescent Self-image. Princeton University Press, Princeton, NJ.

Sacks, J.J., Lockwood, R., Hornreichts, J., Sattin, R.W., 1996. Fatal dog attacks, 19891994. Pediatrics 97, 891-895

Serpell, J.A., 2000. Creatures of the unconscious: companion animals as mediators. In: Podberscek, A.L., Paul, E.S., Serpell, J.A. (Eds.), Companion Animals and Us: Exploring the Relationships between People and Pets. Cambridge University Press, Cambridge, pp. 108-121.

Serpell, J.A., Coppinger, R., Fine, H.A., 2006. Welfare considerations in therapy and assistance animals. In: Fine, H.A. (Ed.), Handbook on Animal-assisted Therapy, second ed. Academic Press, San Diego, pp. 453-474.

Shafton, A., 1995. Dream Reader: Contemporary Approaches to the Understanding of Dreams. SUNY Press, Albany, NY, USA.

Strand, E.B., 2004. Interparental conflict and the youth maladjustment: the buffering effects of pets. Stress, Trauma, and Crisis 7, 151-168.

Taris, T.W., Heesink, J.A.M., Feij, J.A., 1995. The evaluation of unemployment and job searching behaviour: a longitudinal study. Journal of Psychology 129, 301-314.

Trentacosta, C.J., Fine, S.E., 2010. Emotion knowledge, social competence, and behaviour problems in childhood and adolescence: a meta-analytic review. Social Development 19, 1-29.

Van Houtte, B.A., Jarvis, P.A., 1995. The role of pets in preadolescent psychosocial development. Journal of Applied Developmental Psychology 16, 463-479.

Vidovic, V.V., Stetic, V.V., Bratko, D., 1999. Pet ownership, type of pet and socioemotional development of school children. Anthrozoös 12, 211-217.

Vygotsky, L., 1978. Mind in Society. Harvard University Press, Cambridge, MA, USA

Wells, D.L., 2004. The facilitation of social interactions by domestic dogs. Anthrozoös 17, 340-352.

Wells, D.L., 2009. The effects of animals on human health and well-being. Journal of Social Issues 65, 523-543.

Wechsler, D., 1944. The Measurement of Adult Intelligence. Williams and Wilkins, Baltimore.

Wilks, K., 1999. When dogs are man's best friend - the health benefits of companion animals in the modern society. In: Urban Animal Management (UAM) Conference Proceedings Gold Coast.

Williamson, C., 2008. Dolphin assisted therapy: can swimming with dolphins be a suitable treatment? Developmental Medicine and Child neurology 50, 477

Wilson, C.C., Barker, S.B., 2003. Challenges in designing human-animal interaction research. American Behavioral Scientist 47, 16-28.

Zentner, M., Bates, J.E., 2008. Child temperament: an integrative review of concepts, research programs and measures. European Journal of Developmental Science $2,7-37$ 